\title{
Maternal and neonatal outcomes of diabetes in pregnancy in urban women of Sri Lanka: a retrospective cohort study
}

\author{
Fernando TRN ${ }^{1}$
}

\begin{abstract}
Introduction: Maternal diabetes has been recognised for adverse maternal and perinatal outcomes. Aims of this study were to the mode of delivery, maternal morbidity, neonatal morbidity and mortality in pregnant diabetes (DM) women with normal pregnant women.
\end{abstract}

Methods: This was a retrospective cohort study. Data has been gathered from medical records of diabetes (DM) delivered in ward 5, Castle Street Hospital (CSHW), during six months period from 15th May 2012. Patients with compare previously known DM and Gestational DM (GDM) delivered in this unit were included. Parity matched control sample was selected by convenient samling to compare the outcomes.

Results: A total of 270 mothers were enrolled. There were 135 women in each group. Polyhydramnios and pregnancy induced hypertension was found in significantly higher proportion of women in the DM group $(p<0.05)$. Induction of labour rate was significantly higher in the DM group compared to the controls. Elective caesarean section rate was significantly higher in the DM group but there was no difference in the emergency caesarean rates in the two groups. Rates of prematurity, low birth weight, macrosomia, intrauterine growth restriction, still births and neonatal deaths were not significantly different in the two groups. Neonatal pyrexia and neonatal hypoglycaemia were significantly higher in the DM group compared to the controls $(p<0.05)$. From the DM group there were more admissions $(n=5)$ to neonatal unit with prematurity than the control group $(n=1)$.

Conclusion: As expected induction of labour rates and elective caesarean rates were higher among mothers with gestational diabetes. However, there was no significant difference of macrosomia but increased neonatal hypoglycaemia and pyrexia among GDM was noted in this study.

Key words: Diabetes in pregnancy, South Asian women, perinatal outcomes in diabetes mothers.

\section{INTRODUCTION}

Diabetes is the commonest endocrine disorder in pregnancy. The prevalence of Diabetes is rising in South Asian countries during the last couple of decades ${ }^{1}$. Hyperglycaemia during pregnancy can increase foetal and neonatal morbidity and mortality. Australian Carbohydrate Intolerance Study in Pregnant Women (ACHOIS) reported, treatment of GDM significantly reduce perinatal

\footnotetext{
1 Department of gynaecology and obstetrics, faculty of Medicine and allied sciences, Rajarata University of Sri Lanka.
}

\section{Correspondence: T. Romanie N. Fernando}

E-mail: romaniefernando@yahoo.com

Competing interests: None morbidity, including rates of macrosomia, shoulder dystocia, Caesarean section and hypertensive disorders ${ }^{2}$.

Diagnosing and treating GDM will prevent maternal, perinatal and long term complications to both mother and the offspring 3 . High prevalence of type II DM and GDM in Sri Lankan ${ }^{4}$ women of South Asian origin makes them susceptible to adverse effects of hyperglycaemia if remained undiagnosed during pregnancy. Maternal hyperglycaemia in early pregnancy increases the risk of birth defects and miscarriage in type I or II diabetes ${ }^{5}$. In Gestational diabetes hyperglycaemia occurs in the second half of the pregnancy, increase the risks of accelerated foetal growth, late stillbirth, birth trauma and neonatal hypoglycaemia ${ }^{6}$. The risk of late unexpected stillbirth among women with diabetes is approximately fourfold higher when untreated compared to non-diabetic population after 40 weeks of period of amenorrhoea ${ }^{7}$.

Diabetic women are at increased risk of pregnancy induced hypertension and preeclampsia ${ }^{8}$. Women who had been diabetic for years before pregnancy are at higher risk of micro vascular disease such as hypertension, nephropathy and retinopathy ${ }^{9}$. Micro albuminuria or proteinuria indicates renal micro vascular involvement with increased risk of placental insufficiency, pre eclampsia and preterm delivery ${ }^{3}$.

This study was designed to compare the maternal and neonatal outcomes (during the hospital stay) of women with diabetes and non-diabetes in pregnancy among urban women in Sri Lanka.

\section{MATERIALS AND METHODS}

Data collected from medical records of diabetes (DM) delivered in labour room C, CSHW, during six months period starting from 15th May 2012. Inclusion criteria: previously known DM and GDM delivered in this unit. Parity matched control sample to compare the outcomes was selected by convenient sampling. The study design was a retrospective cohort study. All women selected for cases and controls have had a $75 \mathrm{~g}$ oral glucose tolerant test (OGTT) during their pregnancy.

New values for $75 \mathrm{~g}$ OGTT recommended by the International Association of Diabetes and Pregnancy Study Group (IADPSG) were taken as standards for inclusion criteria. IADPSG criteria for diagnosing GDM is as follows: fasting blood glucose (FBS) $5.1 \mathrm{mmol} / \mathrm{L}(92 \mathrm{mg} / \mathrm{dl}), 1$ hour plasma glucose $10 \mathrm{mmol} / \mathrm{L}(180 \mathrm{mg} /$ 
dl) and 2 hour plasma glucose $8.5 \mathrm{mmol}$ /L (153 mg / dl). If one value of the three samples OGTT was above the threshold the woman was diagnosed as GDM. Those women diagnosed as DM in pregnancy were followed up with blood sugar series at regular intervals and treatment was decided accordingly. All women selected to the DM group had good compliance to their individual treatment protocols. Four women were excluded from the DM group as their compliance to treatment was doubtful. Ethical clearance was obtained from the ethic review committee of Castle Street Hospital for women, Colombo.

\section{STATISTICAL ANALYSIS}

Phenotypic data were directly entered into an electronic database and manually verified for errors. In the analysis, summary values are presented as the mean [standard deviation (SD)] when data were normally distributed, and as the median (inter quartile range) when not distributed normally. Student's t-test was used to test for differences between groups where the data were normally distributed. Chi square test and Fisher's exact test were used to compare frequencies and proportions when categorical data are presented as percentage distributions. P value $<0.05$ was taken as the level of significance.

\section{RESULTS}

Total number of deliveries during the six months study period was 1264 . Total sample size 270 women with 135 diabetic women and 135 parity matched normal pregnant women. There were 15 women previously diagnosed as type II DM and 120 diagnosed as GDM during pregnancy. The percentage of DM in pregnancy in this study was $10.6 \%$. Percentage of GDM was $9.4 \%$ and pre- pregnancy DM was $1.2 \%$.

Polyhydramnios at term was the commonest maternal complication in pregnancy in the DM women with $16(11.8 \%)$ women and only four $(2.9 \%)$ in the control group $(\mathrm{p}<0.01)$. Pregnancy induced hypertension without protein urea was the second frequent complication in eleven $(8 \%)$ of DM women $(p=0.02)$ compared to the controls having only three $(2.2 \%)$. Other antenatal maternal complications were preterm labour (3 in DM versus none in the controls), hypothyroidism (2 in DM versus one in the controls) and anaemia (one in the DM versus two in the controls) with no statistical difference in both groups. Oligohydramnios was detected in four women in the DM group versus six women in the control group $(\mathrm{p}=0.3)$.

There were $16(11.8 \%)$ women with high Fasting $(>110 \mathrm{mg} / \mathrm{dl})$ or 2 hour postprandial blood glucose $(>140 \mathrm{mg} /$ dl) in the GDM group 48 hours after delivery. Primary postpartum haemorrhage was the commonest postpartum complication found in the control group with four women and only one in the DM group $(p=0.1)$.

Comparison of mean, standard deviation of birth weight and the period of amenorrhoea at delivery is given in table 1 . Comparison of onset of labour and induction of labour, mode of delivery in the two groups and neonatal out comes are given in table 2, 3, 4 respectively. Shoulder dystocia was not encountered in this study population.

Descriptive data of seven neonates admitted to neonatal unit in the DM group and neonatal unit admissions of seven neonates in the control group are given in table 5 and 6 respectively. The duration of stay in the neonatal unit was similar in both groups, with a mean of 3 days and the range 1-5 days (when the 29 week extreme premature neonate was excluded in the DM group). There were only two birth defects in the whole study group with a cleft palate and a cystic hygroma in neonates of GDM mothers.

\section{DISCUSSION}

Diabetes in pregnancy has adverse maternal and perinatal outcomes compared to normal pregnancy ${ }^{10}$. This study found that in women with DM in pregnancy had a significantly higher frequency of polyhydramnios and pregnancy induced hypertension compared to controls. Polyhydramnios was defined as amniotic fluid index of $20 \mathrm{~cm}$ or more. This is a common complication in GDM women when glycaemic

Table 1: comparison of mean, standard deviation (SD) of birth weight (BW) and period of amenorrhoea (POA) at delivery

\begin{tabular}{|lcccc|}
\hline & \multicolumn{2}{c}{ BW $(\mathrm{Kg})$} & \multicolumn{2}{c|}{ Delivery POA (weeks) } \\
\cline { 2 - 6 } & DM & controls & DM & controls \\
\hline Mean & 2.95 & 3.05 & 37.2 & 38.4 \\
\hline SD & 0.52 & 0.49 & 1.2 & 3.2 \\
\hline P value & \multicolumn{3}{c}{$<0.01^{*}$} \\
\hline * indicates the two groups are significantly different & 0.10 \\
\hline
\end{tabular}

\begin{tabular}{|lccc|}
\hline \multicolumn{4}{|c|}{ Table 2: comparison of onset of labour and induction of Labour (IOL) } \\
\hline Onset of labour & DM n (\%) & Controls n (\%) & P value \\
\hline spontaneous & $13(10 \%)$ & $66(49 \%)$ & $<0.01^{*}$ \\
\hline Induction & $58(43 \%)$ & $21(16 \%)$ & $<0.01^{*}$ \\
\hline Emergency LSCS after IOL & $13(22 \%)$ & $7(33 \%)$ & 0.32 \\
\hline LSCS (lower segment caesarean section), $\mathrm{n}$ (number) & & \\
\hline
\end{tabular}

\begin{tabular}{|c|c|c|c|}
\hline \multicolumn{4}{|c|}{ Table 3: comparison of mode of delivery } \\
\hline Mode of delivery & $\mathrm{DM} n(\%)$ & Controls n (\%) & $P$ value \\
\hline Normal vaginal delivery & $57(42 \%)$ & $71(53 \%)$ & $<0.01^{*}$ \\
\hline Forceps delivery & 00 & 01 & \\
\hline Elective LSCS & $59(44 \%)$ & $42(31 \%)$ & $<0.05^{\star}$ \\
\hline Emergency LSCS & $19(14 \%)$ & $21(16 \%)$ & 0.73 \\
\hline
\end{tabular}




\begin{tabular}{|lccc|}
\hline \multicolumn{4}{|c|}{ Table 4: comparison of neonatal out comes } \\
\hline \multicolumn{1}{|c|}{ Neonatal outcomes } & DM $\mathbf{n}(\%)$ & Controls $\mathbf{n}(\%)$ & P value \\
\hline Macrosomia ( $\geq 3.5 \mathrm{~kg} \mathrm{BW})$ & $20(15 \%)$ & $22(16 \%)$ & 0.72 \\
\hline Low BW $(\leq 2.5 \mathrm{Kg} \mathrm{BW})$ & $24(18 \%)$ & $17(13 \%)$ & 0.68 \\
\hline Intra uterine growth restriction (IUGR) & $05(4 \%)$ & $08(6 \%)$ & 0.39 \\
\hline Admission to NNU & $07(5 \%)$ & $07(5 \%)$ & 0.77 \\
\hline Prematurity (<37 weeks) & $07(5 \%)$ & $03(2 \%)$ & 0.19 \\
\hline Hypoglycaemia & $07(5 \%)$ & $01(0.7 \%)$ & $0.03^{*}$ \\
\hline Still births \& neonatal deaths & $01(0.7 \%)$ & $01(0.7 \%)$ & 0.77 \\
\hline Neonatal pyrexia & $05(4 \%)$ & 00 & $0.02^{*}$ \\
\hline NNU (neonatal unit) & & \\
\hline
\end{tabular}

the neonatal intensive care is more if delivered early by elective caesarean section $^{11}$.

Hypoglycaemia (plasma glucose $\leq 50 \mathrm{mg} / \mathrm{dl}$ ) a known complication of neonates of DM mothers was significantly higher in DM group compared to controls with in the first 24 hours of delivery (table 4). Neonatal hypoglycaemia is a consequence of persistent fetal hyper-insulinaemia occurring after birth when the maternal transfer of glucose has ceased. This study also found neonatal pyrexia to be significantly higher in

Table 5: descriptive data of neonatal unit admissions of seven neonates in the DM group

\begin{tabular}{|lcll|}
\hline $\begin{array}{c}\text { BW } \\
\mathbf{( K g})\end{array}$ & $\begin{array}{c}\text { POA at } \\
\text { delivery }\end{array}$ & Mode of delivery & \multicolumn{1}{c|}{ Complications } \\
\hline 1.15 & 29 & $\begin{array}{l}\text { Pre Term Vaginal } \\
\text { Delivery (PTVD) }\end{array}$ & $\begin{array}{l}\text { Premature pre labour rupture of membranes } \\
\text { (PPROM), Preterm labour (PTL), Prematurity }\end{array}$ \\
\hline 1.6 & 35 & Emergency LSCS & $\begin{array}{l}\text { Pre eclampsia, Growth restriction (IUGR), } \\
\text { Prematurity }\end{array}$ \\
\hline 1.75 & 35 & PTVD & Prematurity \\
\hline 1.75 & 36 & Elective LSCS & IUGR, Prematurity \\
\hline 2.36 & 35 & Emergency LSCS & Foetal distress, Prematurity \\
\hline 2.94 & 38 & Emergency LSCS & Foetal distress, Neonatal anaemia \\
\hline 3.2 & 36 & Elective LSCS & Transient tachypnoea of the new born (TTN) \\
\hline
\end{tabular}

control is sub optimal. However there was no increase perinatal morbidity or mortality in these women. Although pregnancy induced hypertension was significantly higher in the DM group this was not associated with pre eclampsia. The presence of type II DM was $1.2 \%$ and none of these women had micro vascular disease detected during the current pregnancy, the duration of disease ranged from 0.5 years to 7 years prior to present pregnancy.

The mean delivery POA in the DM group was 37 weeks and two days $(\mathrm{SD}=1.2)$, this was significantly low compared to the 38 weeks and four days $(\mathrm{SD}=3.4)$ in the controls (table 1). This difference can be attributed to the higher rate of induction of labour in the DM group 43\% compared to $16 \%$ in controls (table 2). Also the significantly high elective caesarean rate $(44 \%)$ in the DM group compared to $31 \%$ in the controls too may contribute to the lower mean POA at delivery in the DM (table 3). No significant different of the mean BWs were found, the lower mean POA at delivery of DM mothers may have been a contributory factor (table 1).

Neonatal complications such as macrosomia (BW $\geq 3.5 \mathrm{Kg}$ ), prematurity, intra uterine growth restriction, still births and neonatal deaths were not statistically different in DM compared with controls (table 4). These findings could be attributed to the good treatment compliance of the DM mothers, an optimal glycaemic control during the pregnancy and timely delivery. Although there was no statistical significant increase of prematurity in the DM group of the five premature infants needing intensive care admissions, only two had preterm labour, two emergency sections for pre eclampsia and fetal distress, the other was an elective delivery (table 5). The elective delivery of DM with a normal glycaemic control should be delayed up to 39 completed weeks as evidence show respiratory morbidity in neonates, requiring admission to the DM group compared to controls (table 4).

Sixteen (11\%) women had high fasting and post prandial blood glucose 48 hours after delivery; they were not previously known type II DM. Majority of the GDM women will subsequently become type II $\mathrm{DM}^{12}$. Life style changes to minimize weight gain with physical activity and diet had shown to slow the progression to type II DM in these women ${ }^{12}$.

Maternal diabetes with suboptimal glycaemic control can influence aspects of fetal metabolic programming and an increased risk of type 2 diabetes in adult life ${ }^{13}$. Therefore diagnosing DM and optimal glycaemic control during pregnancy will minimise the short term and long term complications to the offspring of DM mothers.

\section{ACKNOWLEDGEMENTS}

1. Dr. YAG Perera, consultant obstetrician and gynaecologists, for assistance given to carry out the study in ward 5 and 6 Castle street hospital for women, Colombo 8.

2. Dr. AGPM Padeniya, Medical officer De soysa hoapital for women, Colombo, for the assistance given for data processing.

3. Dr. PK Abeysundara, Medical officer, base Hospital Negombo, for the advice given on statistical analysis. 


\section{REFERENCES}

1. Wild S, Roglic G, Green A, Sicree $\mathrm{R}$, King $\mathrm{H}$. Global prevalence of diabetes: estimates for the year 2000 and projections for 2030. Diabetes Care 2004; 27: 1047 - 53.

2. Cowther CA, Hiller JE, Moss JR, MacPhee AJ, Robinson JS. Effects of treatment of gestational diabetes mellitus on pregnancy outcomes. New England Journal of Medicine; 2005;352:2477-86

3. González-Quintero VH, Istwan NB, Rhea DJ, Rodriguez LI, Cotter A, Carter J, etal. The impact of glycemic control on neonatal outcome in singleton pregnancies complicated by gestational diabetes. Diabetes Care. 2007 Mar;30(3):467-70.

4. Cockram CS. The epidemiology of diabetes mellitus in the AsiaPacific region. Hong Kong Medical Journal. 2000 Mar;6(1):4352.
5. Jovanovic L, Pettitt DJ. Gestational diabetes mellitus. Journal of American Medical Association; 2001: 286:2516-2518.

6. Negrato CA, Mattar R, Gomes $\mathrm{MB}$. Adverse pregnancy outcomes in women with diabetes. Diabetology and metoabolic syndrome journal. 2012.4:41-56.

7. Lauenborg J, Mathiesen E, Ovesen P, Westergaard JG, Ekbom P. Audit on stillbirths in women with pregestational type 1 diabetes. Diabetes Care 2003.(26), 1385-9.

8. Evers IM, de Valk HW, Visser GHA. Risk of complications of pregnancy in women with type 1 diabetes: nation wide prospective study in the Netherlands. British Medical Journal. 2004. 325:915918.

9. Diabetes control and complications trail research group. The effect of intensive diabetes treatment on the progression of diabetic retinopathy in insulindependent diabetes. Archieves of ophthalmology. 1995.113:36-51.

10. Casson IF, Clarke CA, Howard $\mathrm{CV}$, McKendrick O, Pennycook $S$, Pharoah PO, etal. Outcomes of pregnancy in insulin dependent diabetic women: results of a five year population cohort study. British Medical journal. 1997 August 2; 315(7103): 275-278.

11. Stutchfield $P$, Whitaker $R$, Russell I; Antenatal Steroids for Term Elective Caesarean Section (ASTECS) Research Team. Antenatal betamethasone and incidence of neonatal respiratory distress after elective caesarean section: pragmatic randomised trial. BMJ 2005;331:662.

12. Dornhorst $\mathrm{A}$ and Williamson $\mathrm{C}$. Diabetes and endocrine disease in pregnancy. Deshurst's test book of obstetrics and gynaecology 7th edition. Page 253.

13. Nold JL, Georgieff MK. Infants of diabetic mothers. Pediatric Clinics of North Amrica. 2004 Jun;51(3):619-37. 